\title{
Community, the very idea!: perspectives of participants in a demand-side community energy project
}

\author{
Kevin Burchell* \\ Policy Studies Institute, University of Westminster \\ Ruth Rettie \\ Kingston University \\ Tom C Roberts \\ Kingston University
}

\begin{abstract}
Although community action on energy is now championed by both government and grassroots actors, it has a more ambiguous place in social science commentaries. While the strengths of community action are often said to lie in its collective, local and independent nature, evocations of power relations and conflict are also often present in social science analyses of community-owned renewables schemes. In this brief paper, we examine the meanings of community and community action from the perspective of participants in a demand-side community energy project. Understanding these meanings - particularly the ways they might differ from those in mainstream discourses and in work on the supply-side - is an important issue for policy and practice. Smart Communities was a demand-side, community action project on energy consumption reduction (2011-2013). Drawing on the principles of action research, our analysis is based upon 35 interviews with project participants and experiences during the project action. In Smart Communities, some familiar ambiguities emerged around the collective connotations of community. However, the notions of a local and noncommercial project were widely valued by participants; in particular, these rendered the project more authentic and trustworthy. Particularly in the context of demand-side action in which widespread local participation is important, these findings suggest that there is value in policy-makers and grassroots practitioners engaging with the nuanced reality of community and community action. In addition, the findings raise questions about the UK government's vision for greater commercial collaboration in community energy, and the central role of the private sector in other energy demand reduction policies (such as the Green Deal and the Smart Meter roll-out).
\end{abstract}

Key words: Community energy, demand-side, community action, local, non-commercial. 


\section{Introduction}

The term 'community energy' is increasingly used to denote a wide range of local and community-based activities relating to the production and consumption of energy. The ideas that form the basis of contemporary community energy emerged in the 1970s; for example: 'soft energy path' (Lovins, 1976); 'small is beautiful' (Schumacher, 1974); 'appropriate technology' (Dunn, 1978), and in the efforts of 'alternative technology' activists since then (Smith, 2005). Community-owned generation from renewable sources emerged in government policy between 2000 and 2003 (Walker et al., 2007) and demand-side community action was first mooted in the government's 2005 sustainable development strategy (HM Government, 2005). Supply- and demand-side community energy has been a prominent theme in government policy and action on energy and carbon since 2009 (Ipsos Mori-Department of Energy and Climate Change (DECC), 2009; HM Government-DECC, 2009; Greater London Authority, 2010; ESRC, 2010; HM Government-DECC, 2011; DECC, 2012), and these developments are supported in a number of reports by national third sector organisations (Centre for Sustainable Energy, 2007; Institute for Public Policy Research, 2011; Royal Society for the Arts, 2010). The UK government published its first dedicated Community Energy Strategy in 2014 (DECC, 2014a), encompassing community action on renewables, consumption reduction, collective purchasing and demand management. Seyfang et al's (2013) community energy survey identifies a burgeoning, diverse and largely successful - if vulnerable - sector (also see DECC, 2014b), and DECC's (2014a) strategy aims for considerable growth, based primarily on community-private-public partnership models, and developing capability and capacity through knowledgesharing.

Walker (2011) has pointed out that the value of community and community action in the energy domain often appears to be taken for granted by policy and grassroots actors alike. This commitment continues; for instance, in the Ministerial Foreword to DECC's Community Energy Strategy, community action is discussed in these terms:

We want to play to the advantages that community-based action offers energy and climate change policy. Communities are often more effective in reaching the vulnerable in society and may be more trusted by sceptical consumers. They are better placed to maximise the benefits of certain renewable technologies, such as district heat networks, and can gain wider benefits such as local economic regeneration and a stronger sense of community. Throughout this Strategy we have tried to identify where communities have a genuine advantage or can provide something extra. (DECC, 2014a: 3)

On the grassroots side, the websites of community energy groups, as well as the growing number of community energy sector umbrella organisations, such as the Transitions Network (Hopkins, 2011) and the Communities and Climate Action Alliance (2014), also focus exclusively on the value of community action on energy. Meanwhile, potential downsides of community action seem to be downplayed. For instance, although the Transitions movement (Hopkins, 2011; Transitions Network, 2014) discusses 'dealing with conflict' this refers to conflict within transitions groups and a recent grassroots seminar report largely dismisses 'local opposition' as climate-denial and 'NIMBYism' (Low Carbon Communities Network, 2014). While these materials certainly address the practical challenges of implementing community energy, the positive connotations of community and community action are not challenged.

In contrast, from a social science perspective that stretches back more than 100 years, the notions of 'community' and 'community action' are more problematic in two key ways (Pahl, 2005; Day, 2006; Delanty, 2010; Crow and Mah, 2012). First, the term 
'community' is enormously difficult to define, said by researchers to be 'elusive and vague', complex and slippery (Day, 2006: 1) and 'contentious' (Pahl, 2005: 621). Second, and more importantly in the context of this paper, the connotations of 'community' are more ambiguous than those to be found in the policy and grassroots materials discussed above. According to Day (2006), positive ideas of place-based 'collaborative action for the common good' - complemented by ideas of belonging and identity - characterise much social science on community up to the 1960s, often as part of a nostalgic search for something that is valuable but disappearing. However, Day continues, reflecting broader developments in social science, the 1960 s brought a contrasting emphasis on power, division, exclusion, conflict and oppression to studies of community.

The literature on community-owned renewables projects reflects this broader picture strongly. With respect to the complexity of the concept itself, researchers have identified six interlinked meanings of community action in community energy materials: a place-based or local activity, an interest-based activity, a community-led and collaborative process with benefits distributed fairly and locally, a mid-scale activity, an actor with agency, and an experimental niche (Peters and Jackson, 2008; Walker and Devine-Wright, 2008; Walker, 2011; Aiken, 2014). While much contemporary social science on community energy is open to the value of community and community action (Heiskanen et al., 2010; Seyfang et al., 2013; Burchell et al., 2014), these more troubling issues are also present in a range of studies of community-owned renewable projects. For instance, Walker et al (2010) note highly varying levels of trust of local project managers among other residents, Cass et al (2010) report on divisions between local supporters and opponents of projects, and both Cass et al (2010) and Cowell et al (2010) report a range of quite divergent interests and objectives among institutional actors, such as developers and local authorities. Capturing these dynamics, Walker (2011) notes 'there can be multiple overlapping and sometimes conflicting communities within a place.' Introducing a temporal dimension, he adds, 'communities can be transient and dynamic, fracturing as events unfold and relationships evolve'.

In addition, again reflecting broader developments in social science, contemporary work on communities also often draws on social constructionist approaches (Cohen, 1985; Day, 2006), and focusses on so-called communities of interest that coalesce around particular issues (Day, 2006; Peters and Jackson, 2008; Walker, 2011). From a social constructionist perspective, community can be considered as something that is imagined as well as real, but also as a potentially powerful discourse or idea. As part of this tradition, some recent work on community energy (Aiken, 2014) and communitybased approaches to sustainability more broadly (McCarthy, 2005) critically analyses the practical and discursive value to government of employing the idea of community action in policy. Above all, this work contends that government exploits the positive connotations of community action as a tool of neoliberal governance that: abdicates unrealistic ambitions to the local level; obscures broader social problems; guides the action of local groups and citizens, and enables the implementation of a broader neoliberal agenda. In a similar vein, Hoffman and High-Pippert (2010) have pointed out that commercial organisations have not been slow to reflect the positive connotations of the community-based frame in their marketing (for recent examples, see the websites of UK energy companies, EDF, 2015; e.on, 2015; npower, 2015; SSE, 2015).

It is a common observation that evidence for the policy value of community action on energy is in short supply, and this remains a current and important question (among recent attempts to respond, see Middlemiss, 2008, 2011; Heiskanen et al., 2010; Hargreaves et al., 2013; Seyfang et al., 2013; Burchell et al., 2014; Saunders et al., 2014). However, in this brief paper, we ask a set of different questions: what do the ideas of community and community action mean to people? Are these ideas engaging 
or off-putting? And, what other associated ideas have resonance with local people? We have already seen that community energy projects can be locally divisive (Walker et al., 2010; Cass et al., 2010; Walker, 2011). Since these studies were carried out in the context of large scale renewable energy installations, we also ask in what ways demand-side community energy might differ? These are important questions, not least from a practical perspective. A diverse set of policy, grassroots and third sector actors has coalesced around the idea that community energy is a good thing. However, the extent to which potential demand-side project participants find the community action approach and framing appealing or off-putting is less clear. With this concern in mind, a further objective of this paper is to provide insights into the ways in which demand-side community energy projects might be best framed within communications designed to recruit and engage large numbers of local people in such projects.

\section{Methods}

Our paper is based on a specific case study, the Smart Communities project, funded by the ESRC-EPSRC Energy and Communities stream of the RCUK Energy Programme (ESRC, 2010). The project was run by the researchers, in collaboration with local groups, and took place in a relatively affluent neighbourhood in Kingston upon Thames in south west London between May 2011 and May 2013. In contrast to the large-scale community-owned renewables projects that were discussed earlier, Smart Communities focused on domestic energy demand reduction based around 'behaviour change' and energy efficiency (with some discussion of household micro-generation). The project action featured: community-based consumption feedback; weekly email communication; a web forum; community workshops; home visits; working with a primary school and library, and collaborating with local groups and experts (see Burchell et al., 2014). The 'community' proposition of the project was reflected in the project name and encapsulated in the strap-lines: Working together to save energy and Don't forget to tell your neighbours. To maximise its appeal, Smart Communities was framed in terms of 'energy saving' as opposed to 'climate change' or 'carbon reduction', and a free energy monitor was offered to all members. Other key attributes that determined the 'style' of the project were: that it was local, informal and friendly; that it was oriented around homes, people and children; that it was non-commercial and university-based; and that it was a collaboration with local partners. This paper draws on 35 interviews with people who joined the project, informal research throughout the project action, an end-of-project survey and the project participant database (see Burchell et al., 2014).

\section{Results}

Among the many interwoven themes that emerged from the interviews, we emphasise four here:

1. The idea of community was expressed in a variety of ways, both positive and negative;

2. More broadly, many project members expressed the broader significance for them of what we can call a sense of being part of something (though this was not necessarily being part of a community specifically);

3. Being part of something remained important for people even when they were not directly interacting with others; 
4. The local and non-commercial characteristics of the project were very important for project members.

However, before we elaborate on these themes, we would like to make a few comments about the overall outcomes of the project. Over the two years some 400 households joined the project (around 16 per cent of the total). Smart Communities suggests that community action on energy over two years can support: knowledge about domestic energy consumption and about the consumption of household appliances, as well as behaviour change and energy efficiency measures. That said, although participation, action and change were extensive in some households, these were limited in many others. For instance, in some cases, change was limited to switching-off lights and not overfilling kettles. In addition, the project shows that when it does take place - energy behaviour change is a complex and lengthy process that involves numerous changes some of which involve time-consuming consideration, information gathering and negotiation between household members. Finally, elements of the project action - in particular, our own networking and the community workshops - helped to develop novel local community energy networks among local residents and local groups. As a direct result of this, the Smart Communities project is now being continued, developed and extended by a local group (see Burchell et al., 2014).

No doubt often taking their lead from the project team, project participants habitually made use of the term 'community' as a straightforward way of describing a group of local people. The need to determine and perhaps enforce a boundary around the project area provoked ongoing anxiety among the project team, and unease among some local people who lived outside of the project area. However, in no sense did the Smart Communities project create conflict or division in the ways that has been noted in the context of community renewable projects. Nonetheless, a variety of the positive and negative connotations of community that were discussed earlier can be observed in the qualitative data. On some occasions, project members told us that they were attracted to the project specifically because it was a community project. For instance, in response to a query about why he joined the project, Norman (a pseudonym) said, 'I think the fact that it was a community thing' and Tom said 'it was quite nice as a sort of community thing'. On the other hand, Tom also ambiguously revealed his aversion to group activities in his explanation, 'I'm not very clubbable', for why he had not attended any of our community workshops. When we asked Chloe about the ways in which she had engaged with the community-based energy consumption feedback, she responded in a manner that reflected the potentially troubling connotations of community that is noted in the literature:

It seemed like one more middle-class competitive thing. I thought they're going to be bragging about consumption saving now at the school gates, along with their genius children and the husband's bonus.

The project data suggests that many, but not all, participants were engaged and motivated by what we can call a sense of being part of something, though this was not necessarily part of a community. For instance, Faith suggested to us that it was important to be part of a local group of people acting on energy:

People as individuals often feel they can't make much of a difference and them putting the lights on or running the drier, well what difference does that make? But obviously as a part of Kingston, you feel you're all doing something.

In more informal conversations, project members also often reflected on the significance to them of being part of a formal project and, in particular, a university 
research project. While common, this was by no means a universal sentiment. For example, Craig told us 'I think it's a good thing to do but it doesn't make me feel part of a wider community of energy savers' and Mervyn explained 'it's not something l'd bring up if I chat to a local neighbour'.

The overall pattern of participation in Smart Communities conformed to a 'pyramid of participation' (Stigsgotter and Grahn, 2002; Chanon, 2009), with an inverse relationship between numbers of participants and extent of participation. For instance, more project members participated in energy monitoring at home (we estimate around 320 , or 80 per cent of the total) than in community activities such as evening workshops or social events (we estimate around 80, or 15 per cent of the total) (see Burchell et al., 2014). There is evidence in the interviews with project members who did not engage with the community activities that it was important to them that these activities were taking place, even though they were not participating in them themselves. In a sense, these participants felt that they were working together, but apart. An illustration of this is provided by Faith who - in common with many parents of young children in the project - told us that she was too busy and tired to attend community workshops and other social events. Nonetheless, Faith was very active within her own home and - as her earlier comment shows - it was important to her that other people in Kingston were acting on energy in the same ways as she was. Tom was also highly active within his own home and - as his earlier comments illustrate he valued the fact that other people were attending community events while he firmly felt that these were not for him.

As mentioned earlier, the Smart Communities project was framed and implemented as a local and non-commercial project. For instance, we collaborated with local third and public sector partners (such as local environmental groups, a local primary school and library); worked with local commercial suppliers as much as possible; through our partners, used local and non-commercial 'experts' in our workshops and home visits; emphasised the local area in which we were working in our communications; provided energy monitors free-of-charge; and, provided all other services and materials free-ofcharge. The importance of the combined local and non-commercial characteristics of the project cannot be overstated. This is because they contributed to the trustworthiness of the project and - more importantly - of the advice and guidance that was offered by the 'experts'. Of course, inter alia, this highlights a strong sense of householder mistrust or at least ambiguity with respect to commercial providers of energy, and energy-related products and services. These themes were most strongly reflected in a set of interviews that were undertaken with project participants who had received Smart Communities' energy advice home visits (see detail in Burchell et al., 2014). These interviewees universally reflected on the trust that was engendered by the local, neighbourly and, particularly, non-commercial characteristics of the 'experts' who delivered the home visits. Sophie's and June's comments on what they valued about the home visits illustrate these issues very well:

Because they're [the 'experts'] enthusiasts and there's nothing pushing it apart from a real desire to save the planet, it's not profit related.

Well, they've got the experience and knowledge, and they'll give you the advice and it's not hard sell. 


\section{Discussion}

In this short paper, we have examined the understandings of the notions of 'community' and 'community action' among participants in the specific context of a demand-side community energy project. In particular, we have commented on: what these ideas mean to people; whether they are engaging or off-putting; whether demand-side community energy might create exclusion and conflict in the ways that supply-side activity clearly can; and what other associated ideas have resonance with project members. The context for this has been a widespread, but possibly simplistic, adherence to an entirely positive understanding of community action on energy across government, grassroots and third sector organisations (despite the presence of a longstanding more nuanced picture of this approach in the social science literature). Indeed, in some cases, the faith in community approaches appears to be so strong that more ambiguous voices are rendered mute.

As we have said, the Smart Communities approach to demand-side action did not create conflict or division in the ways that has been noted in the context of large-scale community renewable projects. However, while it is the case that project members often used the term community as a neutral and descriptive term, it is notable that the notion of community action is more ambiguous in the Smart Communities data than is apparent within policy, grassroots and third sector materials. On the other hand, the local and non-commercial elements of Smart Communities were much more widely appreciated by - and, certainly, important to - project members. At the same time, a broader idea of being part of something - a group of people acting on the same issue or a particular project - was also motivating for project participants. Interestingly, this was often the case even when project members were acting in relative isolation within their own homes rather than actually meeting up or communicating with other project members.

These findings suggest a number of insights that might be of value to actors in policy and practice. In particular, in a variety of ways, these relate to the differences between large-scale community-owned renewable installations on the supply-side and the predominantly demand-side action of Smart Communities. Although Seyfang et al (2013) point out that community energy projects very often combine these activities, this is an important point because this issue has not previously been examined on the demand-side. It is not really surprising that the demand-side activities in Smart Communities did not create the conspicuous conflict or division that has been noted in community-owned renewables projects. This is because the major challenges of largescale wind, solar or hydro installations - relating particularly to the distribution of the costs (such as the loss of amenity that might result from the presence of a large physical structure) but also to the distribution of the benefits (such as income, which might be distributed or spent in a variety of ways) - are largely absent from demandside action. At the same time, of course, it should be remembered that large installations can also act as a focal point around which demand-side action can be built. With respect to loss of amenity, it is worth noting that - towards the end of Smart Communities - the primary school with which we worked turned down the opportunity of a cost-free solar PV installation due to concerns about the impact on its local relationships that might have resulted from any loss of amenity. While this decision caused dismay - and, it has to be said, anger - in the local group that proposed the scheme, it certainly reiterates the challenges related to the idea of community and the practice of community action that have been noted on the supply-side and in the broader social science literature.

However, community action on the demand-side is also different from community renewables in terms of the levels of broad-based participation that it requires. 
Community renewables schemes tend to be driven and implemented by relatively few local people (Walker and Cass, 2007; Seyfang et al., 2013). While the same is true in the initiation of demand-side action, the success of these projects also intrinsically relies on much broader local buy-in and participation in behaviour change and energy efficiency measures across the local population. With this in mind, it is important for community energy practitioners to acknowledge that, while notions of community and collective action might be appealing to them, this is not always the case among the broader local population. This has implications for the range of activities that demandside projects might wish to implement - perhaps necessitating an emphasis on individual or household activities, as well as explicitly community activities - and on the ways in which projects are described in project communications.

The imperative of widespread participation in demand-side action raises a further point. In the course of this paper we have cited two instances in which advocates and practitioners of community energy have responded very negatively to local views that conflict with their own (in the Low carbon Community Network workshop report and our experience relating to a proposal for a solar PV installation at a local school). Of course, these are further examples of the potential for local conflict that are highlighted by Walker (2011) and others. We would not want to overstate this, yet it does appear that there is a danger that some advocates of community energy might be so convinced of the value and 'rightness' of their ideas and proposals that they are unable to engage with divergent voices in a constructive way. It is almost as if the stereotypically rosy connotations of community in concert with the imperative of decarbonisation render all other opinions misguided at best and representing vested interests at worse. With this concern in mind, it does seem to us that the need for engagement by local people in demand-side action might prompt community energy groups to always engage with any local opposition in a way that is accepting of diverse views opinions and levels of engagement.

Our findings also suggest that it is important to implement demand-side projects in ways that are genuinely both local and non-commercial (and to remain mindful of the potentially different meanings of these characteristics and the connotations of community). As we have mentioned, this was very important to the trust that project members placed in the project activities and in particular in the advice that was offered to them by the local 'experts' with whom we worked. Again, there are important distinctions here between larger-scale community renewables projects and demandside action. Large-scale infrastructural projects clearly require the participation of commercial organisations operating at national or even international scales. To this extent, at least, given appropriate financial arrangements, DECC's desire to increasing numbers of community-private partnerships seems reasonable. However, in purely demand-side projects, the explicit involvement of commercial organisations or an overtly commercial orientation would appear to place many of the benefits of community action in jeopardy. These findings - which correspond with Seyfang et al's (2013) - sit somewhat uncomfortably with DECC's emphasis on private sector involvement in community energy, and in other flagship energy demand reduction policies, such as the Green Deal energy-saving home improvements scheme (DECC, 2014c) and the Smart Meter roll-out (DECC, 2014d). In addition, our findings with respect to the importance of local action - which correspond with Walker and DevineWright's (2008) discussions - suggest that grassroots groups should genuinely maximise the local nature of their work and communicate this with prospective participants.

The findings from the Smart Communities project are broadly supportive of the rationale for community energy. At the same time, the project sharply illustrates the challenging and long-term nature of the demand-side changes that DECC envisages 
through community action, and the resultant need for long-term government funding for demand-side community energy activities. This is particularly the case in urban areas where the potential for income through renewables is more restricted (see Burchell et al., 2014). Certainly, the project findings suggest that the notion of community action is often important to project members, even those who do not participate in it themselves. However, at the same time, the project also suggests that a broader sense of being part of something - perhaps a project or a joint endeavour, though not necessarily a community, can also be important. This is a significant insight because it raises the prospect of scaling-up this sense of being part of something in ways other than community action per se. In Smart Communities, it appears that this sense was largely created by the weekly emails that the project team sent to the project members. These were relatively simple - reminding people to enter consumption readings on the project website, providing simple energy saving tips, informing about features of the project - nonetheless, they clearly created a strong and motivating relationship between the project members and the project team. In marketing terms, this phenomenon might be understood as a socially-oriented example of the well-known benefits of what commercial marketers refer to as 'relationship marketing' (which emphasises long-term communications and relationships) (e.g. Kotler and Armstrong, 2012). Our findings in this area suggests that other energy policy initiatives that focus on householders - in particular, perhaps, the Smart Meter roll-out - might benefit from the kinds of relationships that could be created through direct, ongoing and helpful communications from embedded and trustworthy project managers.

Government and grassroots groups clearly hope that community energy will play a major part in the UK's efforts to meet its carbon reduction targets. On the basis of findings in the Smart Communities project, this paper has suggested that policy-makers and grassroots groups in community energy - particularly on the demand-side - might benefit from:

1. More active engagement with the ambiguous connotations of community action;

2. Responding to the evidence that behaviour change and energy efficiency advice is more trustworthy when it comes from sources that are independent and noncommercial;

3. Acknowledging that opposing voices have validity and should be engaged with constructively.

However, as we have mentioned, these insights are based upon one in-depth case study. With this in mind, we recognise the need for further research that attempts to understand the internal dynamics of community energy projects and the ways in which they interact with other social actors, including the ways in which community and community action are understood by project participants. In particular, since Smart Communities examined demand-side action in a relatively affluent suburb, such work might examine demand-side community energy within a more deprived urban area, or combined demand- and supply-side action in a rural area. In addition, we suggest that this work might draw on a broad range of approaches and methods, including the use of other ethnographic methods and the collection and analysis of more detailed consumption data in a demand-side community energy context. 


\section{Acknowledgements}

This research was funded by the ESRC-EPSRC Energy and Communities stream of the RCUK Energy Programme (ES/I006982/1). We are grateful to all of the Smart Communities participants, partners and supporters (see Burchell et al., 2014: 3), and to Hilary Salter for assistance with references. We are also very grateful for the helpful comments from the anonymous reviewer and the editors.

* Correspondence address: Kevin Burchell, k.burchell@westminster.ac.uk

\section{References}

All web links were checked on 06-11-14.

Aiken, G. (2014) (Local-) community for global challenges: carbon conversations, transition towns and governmental elisions. Local Environment, 1-19.

Burchell, K., Rettie, R. and Roberts, T. (2014) Working together to save energy?: final report of the Smart Communities project. http://business.kingston.ac.uk/smartcommunities.

Cass, N., Walker, G. and Devine-Wright, P. (2010) Good Neighbours, Public Relations and Bribes: The Politics and Perceptions of Community Benefit Provision in Renewable Energy Development in the UK. Journal of Environmental Policy \& Planning, 12, 3, 255-275.

Centre for Sustainable Energy (2007) Mobilising individual behaviour change through community initiatives: lessons for tackling climate change. http://www.cse.org.uk/pdf/pub1073.pdf.

Chanon, G. (2009) Local Community Involvement: A Handbook for Good Practice. Luxembourg: Office for the Official Publication of the European Communities. http://www.eurofound.europa.eu/publications/htmlfiles/ef9873.htm.

Communities and Climate Action Alliance (CCAA) (2014) A Community Energy Strategy for the UK - $A$ Community Perspective. http://ccaanet.wordpress.com/2014/01/06/ccaa-paper-on-a-community-energystrategy-for-the-uk/.

Cohen, A. (1985) The symbolic construction of community. London: Routledge.

Cowell, R., Bristow, G. and Munday, M. (2010) Acceptance, acceptability and environmental justice: the role of community benefits in wind energy development. Journal of Environmental Planning and Management, 54, 4, 539557.

Crow, G. and Mah, A. (2012) RESEARCH REPORT: Conceptualisations and meanings of "community": the theory and operationalisation of a contested concept. http://www.community-methods.soton.ac.uk/resources/CC\%20Final\%20Report 30\%20March\%20GC.pdf.

Day, G. (2006) Community in everyday life. London: Routledge.

DECC (2012) Low Carbon Communities Challenge Evaluation Report. http://www.decc.gov.uk/assets/decc/11/tackling-climate-change/saving-energyco2/5788-low-carbon-communities-challenge-evaluation-report.pdf.

DECC $(2014 a) \quad$ Community Energy Strategy: Full Report.
https://www.gov.uk/government/publications/community-energy-strategy.

DECC (2014b) Community Energy in the UK: Part 2. https://www.gov.uk/government/publications/community-energy-in-the-uk-part-2.

DECC (2014c) Green Deal. https://www.gov.uk/green-deal-energy-savingmeasures/overview. 
DECC (2014b) Smart Meters. https://www.gov.uk/government/policies/helpinghouseholds-to-cut-their-energy-bills/supporting-pages/smart-meters.

Delanty, G. (2010) Community. London and New York: Routledge.

Dunn, P. (1978) Appropriate technology: technology with a human face. London: Macmillan.

EDF (2015) EDF Energy's local community initiatives. http://www.edfenergy.com/energyfuture/edf-energys-approach-the-edf-energyvision/local-community-initiatives.

e.on (2015) Community energy. https://www.eonenergy.com/for-yourbusiness/community-energy.

$\operatorname{ESRC}(2010) \quad$ Energy and Communities Collaborative venture. http://www.esrc.ac.uk/research/major-investments/energy-and-communitiescollaborative-venture.aspx.

Greater London Authority (2010) Low Carbon Zones. https://www.london.gov.uk/priorities/environment/tackling-climatechange/developing-low-carbon-zones-to-help-cut-local-emissions

Hargreaves, T., Hielscher, S., Seyfang, G. and Smith, A. (2013) Grassroots innovations in community energy: The role of intermediaries in niche development. Global Environmental Change, 23, 868-80.

Heiskanen, E., Johnson, M., Robinson, S., Vadovics, E. and Saastamoinen, M. (2010) Low-carbon communities as a context for individual behavioural change. Energy Policy, 38, 7586-7595.

HM Government (2005) Securing the future: delivering UK sustainable development strategy. $\quad$ https://www.gov.uk/government/publications/securing-the-futuredelivering-uk-sustainable-development-strategy.

HM Government/DECC (2009) The UK Low Carbon Transition Plan: National strategy for climate and energy http://webarchive.nationalarchives.gov.uk/ 20100509134746/http:/www.decc.gov.uk/en/content/cms/publications/lc tra ns_plan/lc_trans_plan.aspx.

HM Government/DECC (2011) The Carbon Plan: delivering our low carbon future. https://www.gov.uk/government/uploads/system/uploads/attachment data/file /47613/3702-the-carbon-plan-delivering-our-low-carbon-future.pdf.

Hoffman, S. and High-Pippert, A. (2010) From private lives to collective action: recruitment and participation incentives for a community energy program. Energy Policy, 38, 7567-7574.

Hopkins, R. (2011) The Transition Companion: making your community more resilient in uncertain times. Cambridge: UIT/Green Books.

Institute for Public Policy Research (2011) Green streets, strong communities. http://www.ippr.org/publications/green-streets-strong-communities.

Ipsos MORI-DECC (2009) The Big Energy Shift: Report from Citizens' Forums. http://www.ipsos-mori.com/researchpublications/publications/1363/The-BigEnergy-Shift.aspx.

Lovins, A. (1976) Energy Strategy: The Road Not Taken?, Foreign Affairs, http://www.rmi.org/Knowledge-Center/Library/E77-01 EnergyStrategyRoad NotTaken.

Low Carbon Communities Network (2014) Communities and Energy Seminar Report. http://lowcarboncommunities.org/2014/01/03/communities-and-energyseminar-report/.

McCarthy, J. (2005) Devolution in the woods: community forestry as hybrid neoliberalism. Environment and Planning A, 37, 995-1014.

Middlemiss, L. (2008) Influencing individual sustainability: a review of the evidence on the role of community-based organisations. International Journal of Environment and Sustainable Development, 7, 1, 78-93. 
Middlemiss, L. (2011) The effects of community-based action for sustainability on participants' lifestyles. Local Environment, 16, 3, 265-280.

npower (2015) In the community: putting our energy into community. http://www.npower.com/home/about-npower/in-the-community/.

Pahl, R. (2005) Are all communities communities in the mind? The Sociological Review, $53,4,621-640$.

Peters, M. and Jackson, T. (2008) Community Action: A Force for Social Change? Some Conceptual Observations. RESOLVE Working Paper, 01-08. http://resolve.sustainablelifestyles.ac.uk/publications/communityactionaforcefor socialchange

Royal Society for the Arts (2010) Connected communities: how social networks power and sustain the Big Society. http://www.thersa.org/action-researchcentre/reports/socialchange/how-social-networks-power-and-sustain-the-bigsociety

Saunders, C., Büchs, M., Papafragkouc, A., Wallbridge, R. and Smith, G. (2014) Beyond the Activist Ghetto: A Deductive Blockmodelling Approach to Understanding the Relationship between Contact with Environmental Organisations and Public Attitudes and Behaviour. Social Movement Studies, 13, 1, 158-177.

Schumacher, E. (1974) Small is beautiful: a study of economics as if people mattered. London: Sphere.

Seyfang, G., Park, J.J. and Smith, A. (2013) A thousand flowers blooming? An examination of community energy in the UK. Energy Policy, 61, 13, 977-989.

Smith, A. (2005) The alternative technology movement: an analysis of its framing and negotiation of technology development. Human Ecology Review, 12, 2, 106-119.

SSE (2015) Community energy. http://sse.com/beingresponsible/responsible communitymember/communityenergy/.

Stigsdotter, U. and Grahn, P. (2002) What Makes a Garden a Healing Garden? Journal of therapeutic Horticulture, 13, 2, 60-69. http://www.protac.dk/Files/Filer/What_makes_a_garden_a_healing_garden_Stig sdotter U Grahn P.pdf.

Transitions Network (2014) https://www.transitionnetwork.org/support/dealingconflict.

Walker, G. (2011) The role for 'community' in carbon governance. Wiley Interdisciplinary Reviews: Climate Change, 2, 777-78. http://www.research.lancs.ac.uk/portal/en/publications/the-role-for-communityin-carbon-governance(0ee3e004-8780-4ab7-a9aa-630503146007).html.

Walker, G. and Cass, N. (2007) Carbon reduction, 'the public' and renewable energy: engaging with socio-technical configurations. Area, 39, 4, 458-469.

Walker, G. and Devine-Wright, P. (2008) Community renewable energy: What should it mean? Energy Policy, 36, 497-500.

Walker, G., Hunter, S., Devine-Wright, P., Evans, B. and Fay, H. (2007) Harnessing Community Energies: Explaining and Evaluating Community-Based Localism in Renewable Energy Policy in the UK. Global Environmental Politics, 7, 2, 64-82. http://nrl.northumbria.ac.uk/3717/1/Harnessing\%20community\%20energiesexplaining\%20community\%20based\%20localism\%20in\%20renewable\%20energy \%20policy\%20in\%20the\%20UK.pdf.

Walker, G., Devine-Wright, P., Hunter, S., High, H. and Evans, B. (2010) Trust and community: Exploring the meanings, contexts and dynamics of community renewable energy. Energy Policy, 38, 2655-2663. 